\title{
Hypertension in Henoch-Schönlein purpura with minimal urinary findings
}

\author{
P M Drummond, N E Moghal, M G Coulthard
}

\begin{abstract}
Though hypertension is a common feature of Henoch-Schönlein purpura (HSP) acute nephritis, it is seen only rarely and transiently if renal function is normal and abnormal urinary findings are minimal. We report a 3.4 year old girl who had the typical arthritis and rash of $\mathrm{HSP}$, but also had significant hypertension with only minimal urinary findings. Imaging investigations revealed one normal kidney, and one that was almost destroyed from previous reflux nephropathy; her hypertension resolved after unilateral nephrectomy. Other causes of hypertension should be excluded in children with HSP and minimal urinary findings.

(Arch Dis Child 2001;84:163-164)
\end{abstract}

Keywords: Henoch-Schönlein purpura; nephritis; hypertension

Renal involvement in Henoch-Schönlein purpura (HSP) is common, with an incidence of $20-50 \%$. $^{1}$ The variation in estimates is probably related to differences in referral patterns to reporting units, in criteria for diagnosing HSP, and in the assessment of renal involvement. Renal involvement is usually minimal, with no more than transient microscopic haematuria, and in these cases blood pressure and renal function are usually normal. Hypertension typically occurs as part of acute HSP nephritis, with impaired renal function, and often oliguric hypervolaemia. However, six children have been reported with minimal or no evidence of

Accepted 1 September 2000

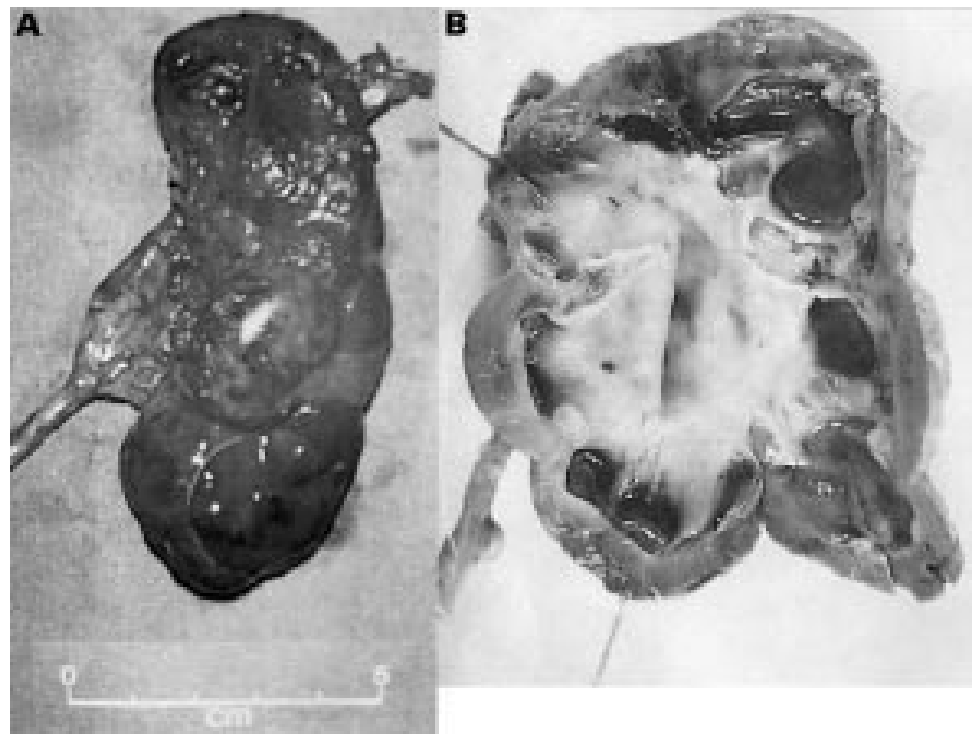

Figure 1 Nephrectomy specimen. (A) Fresh; (B) after fixation and sectioning. renal involvement who had hypertension that resolved on resolution of the HSP. ${ }^{23}$ Because of this, it has been recommended that children with HSP, hypertension, and minimal urinary findings should not be investigated for another cause of their hypertension unless it persists after the resolution of their $\mathrm{HSP}^{2}$ We describe a case where such a child was investigated early, and another cause for her hypertension was found and treated before her HSP had resolved.

\section{Case report}

A previously well, normally grown (40th centiles for height and weight) 3.4 year old girl presented with HSP and hypertension with minimal renal involvement. She had had swollen, tender knee, wrist, and metacarpophalangeal joints for five days, a typical palpable purpuric HSP rash on her legs and buttocks for 24 hours, and oedema of her scalp and forehead. Her blood pressure, measured by auscultation and using the largest cuff that would fit on her upper arm was $130 / 100 \mathrm{~mm} \mathrm{Hg}$; the systolic value was confirmed by Doppler ultrasound as ranging between 130 and $150 \mathrm{~mm} \mathrm{Hg}$. Fundoscopy was normal. Her plasma creatinine concentrations were normal throughout, varying between 56 and $61 \mu \mathrm{mol} / \mathrm{l}$, equivalent to a glomerular filtration rate of about 80 $\mathrm{ml} / \mathrm{min} / 1.73 \mathrm{~m}^{2},{ }^{4}$ and her urea and electrolyte concentrations and full blood count were normal. Urine stick testing showed trace to $1+$ blood, and 1+ proteinuria; phase contrast microscopy showed only occasional glomerular red blood cells. The early morning urinary protein:creatinine ratio was slightly raised at 67 $\mathrm{mg} / \mathrm{mmol}$ (normal <20). An autoantibody screen, including rheumatoid factor, C3 and C4 complement, and serum immunoglobulin concentrations were all normal.

Although she remained clinically well with only minimal arthralgia, her hypertension persisted, and she was transferred to our regional paediatric nephrology unit. Her blood pressure was controlled with $0.3 \mathrm{mg} / \mathrm{kg}$ nifedipine three times daily and $1 \mathrm{mg} / \mathrm{kg}$ atenolol daily. Because her hypertension seemed out of proportion to her degree of HSP nephritis, we investigated her for other causes. Ultrasound examination revealed a normal right kidney and a very small left one with moderate pelvicalyceal dilatation and clubbing, urothelial thickening, and thin parenchyme. The Doppler trace was normal on the right and could not be obtained on the left, indicating a much lower blood flow in that kidney. A dimercaptosuccinic acid scan showed a normal right kidney, and an irregular left kidney which contributed only $9 \%$ of the total 
renal function. She underwent an elective left nephrectomy (fig 1). The histology was diagnostic of reflux nephropathy, and showed no features of dysplasia or HSP; glomerular staining for IgA was negative.

Post-nephrectomy, her systolic blood pressure is normal at $90 \mathrm{~mm} \mathrm{Hg}$ without any medication, and her urinary albumin:creatinine ratio is normal at $8.0 \mathrm{mg} / \mathrm{mmol}$. However, she has continued to develop new crops of HSP skin lesions.

\section{Discussion}

As hypertension has been described as occurring in six children with HSP without renal impairment or urinary abnormalities, ${ }^{23}$ it has been suggested that it is reasonable to defer an extensive evaluation for severe hypertension in this setting until well after the other manifestations of HSP have resolved. ${ }^{2}$ However, considering that HSP with minimal nephritis is relatively common, the reported frequency of associated hypertension makes this a very rare complication. It is probably less common than the 1 in 1000 incidence of asymptomatic hypertension identified by performing routine blood pressure measurements in ill children. ${ }^{5}$ The commonest cause of unsuspected hypertension in children is scarring from reflux nephropathy. ${ }^{5}$ We would therefore argue that delaying investigations for other causes of hypertension in a child with mild HSP nephritis is inappropriate, especially as the initial imaging tests are minimally invasive and HSP may take a very long time to resolve. In the case we describe, the child continued to crop HSP rashes for months after she had received definitive treatment for her hypertension.

1 White RHR. Henoch-Schönlein purpura. In: Churg A, Churg J, eds. Systemic vasculitides. New York: Igaku-Shoin, 1991:203-17.

2 Whyte DA, Van Why SK, Seigel NJ. Severe hypertension without urinary abnormalities in a patient with HenochSchönlein purpura. Pediatr Nephrol 1997;11:750-1.

3 Truttman AC, Beretta-Piccoli BC, Carvajal-Busslinger MI, Bianchetti MG. Arterial hypertension with normal urinalysis in Henoch-Schönlein disease: a further case. Pediatr Nephrol 1998;12:523-5.

4 Schwartz MD, Haycock GB, Edelmann CMJ, Spitzer A. A simple estimate of glomerular filtration rate in children derived from body length and plasma creatinine. Pediatrics 1976;58:259-63.

5 Gonasekera CDA, Dillon MJ. Measurement and interpretation of blood pressure. Arch Dis Child 2000;82:261-5.
Answers on $p 187$.

Departments of Paediatrics and Respiratory Medicine, Guy's Hospital, St Thomas' Street, London SE1 9RT, UK

Louise Denvir

Mike Polkey

Dipak Kanabar
A previously fit and well 15 year old suffered a near drowning episode in seawater.

Her initial blood gas was: $\mathrm{pH} 7.04, \mathrm{pCO}_{2} 12.2$ $\mathrm{kPa}, \mathrm{po}_{2} 8.97 \mathrm{kPa}, \mathrm{HCO}_{3} 24 \mathrm{mEq} / \mathrm{l}, \mathrm{BE}-10$.

Her spirometry, carried out on day 10 , and subsequently, showed both a restrictive and obstructive picture.

Her chest $x$ ray was as shown in fig 1 .

Questions

1. What is the differential diagnosis on the basis of the $x$ ray and the lung function tests?

2. Nursing staff who suctioned her, noted sand in suction catheters while she was ventilated. What investigations would be appropriate next?

3. What is the management of this condition and how common is it?

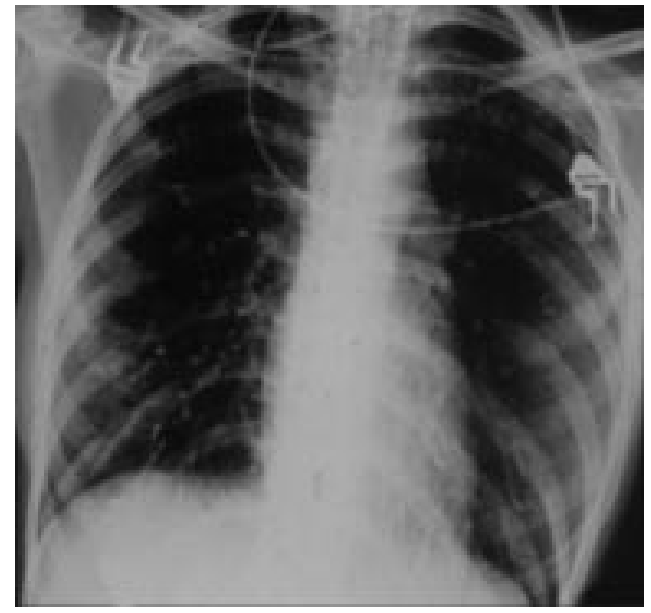

Figure 1 